\title{
Expression of CD74 is increased in neurofibrillary tangles in Alzheimer's disease Kathryn J Bryan ${ }^{1}$, Xiongwei Zhu ${ }^{1}$, Peggy L Harris ${ }^{1}$, George Perry ${ }^{1,2}$, Rudy J Castellani ${ }^{3}$, Mark A Smith ${ }^{1}$ and Gemma Casadesus ${ }^{* 4}$
}

Address: ${ }^{1}$ Department of Pathology, Case Western Reserve University, Cleveland Ohio, USA, ${ }^{2}$ College of Sciences, University of Texas at San Antonio, San Antonio, Texas, USA, ${ }^{3}$ Department of Pathology, University of Maryland, Baltimore, Maryland, USA and ${ }^{4}$ Department of Neurosciences, Case Western Reserve University, Cleveland Ohio, USA

Email: Kathryn J Bryan - kathryn.bryan@case.edu; Xiongwei Zhu - xiongwei.zhu@case.edu; Peggy L Harris - peggy.harris@case.edu; George Perry - george.perry@case.edu; Rudy J Castellani - rcastellani@som.umaryland.edu; Mark A Smith - mark.smith@case.edu; Gemma Casadesus* - gemma.casadesus@case.edu

* Corresponding author

Published: II September 2008

Molecular Neurodegeneration 2008, 3:13 doi:10.1186/1750-1326-3-13
Received: 20 March 2008

Accepted: II September 2008

This article is available from: http://www.molecularneurodegeneration.com/content/3/1/13

(C) 2008 Bryan et al; licensee BioMed Central Ltd.

This is an Open Access article distributed under the terms of the Creative Commons Attribution License (http://creativecommons.org/licenses/by/2.0), which permits unrestricted use, distribution, and reproduction in any medium, provided the original work is properly cited.

\begin{abstract}
Alzheimer disease $(A D)$ is a chronic neurodegenerative disease that is characterized by progressive memory loss. Pathological markers of $A D$ include neurofibrillary tangles, accumulation of amyloid$\beta$ plaques, neuronal loss, and inflammation. The exact events that lead to the neuronal dysfunction and loss are not completely understood. However, pro-inflammatory cytokines, such as interleukin-I $\beta$, interleukin- 6 , and tumor necrosis factor $\alpha$, are increased in $A D$, along with gene expression of major histocompatibility complex (MHC) class II molecules and macrophage migration inhibitory factor (MIF). MHC class II molecules are found in microglia of the brain, while MIF is found in both microglia and neurons of the hypothalamus, hippocampus, and cortex. MIF is not only a lymphocyte mediator but also a pituitary factor with endocrine properties and can mediate phosphorylation of the extracellular signal-regulated kinase-I/2 MAP kinases pathway. In this study, we looked at CD74, an integral membrane protein that acts as both a chaperone for MHC class II molecules as well as a receptor binding site for MIF. CD74 was recently found to be increased in microglia in $A D$ cases compared to age-matched controls, but has not been reported in neurons. In our analysis, immunohistochemistry revealed a significant increase in CD74 primarily in neurofibrillary tangles, amyloid- $\beta$ plaques, and microglia. This is the first finding to our knowledge that CD74 is increased in neurons of AD cases compared to age-matched control cases.
\end{abstract}

\section{Background}

Alzheimer disease (AD) is a chronic neurodegenerative disease that is pathologically characterized by neurofibrillary tangles (NFT), accumulation of amyloid- $\beta(\mathrm{A} \beta)$, and increased inflammatory markers. However, many lines of evidence suggest that mitogenic signaling, sex steroids, oxidative stress and inflammation may also play a role in the pathogenesis of the disease [1-3]. Increased inflammation has been associated with cognitive decline in $\mathrm{AD}$. Pro-inflammatory markers, such as interleukin-1 $\beta$ (IL$1 \beta)$, interleukin-6 (IL-6), and tumor necrosis factor $\alpha$ $(\mathrm{TNF} \alpha)$ are not only increased in $\mathrm{AD}$ patients, but also increase $A \beta[4,5]$. The accumulation of $A \beta$ then induces a pro-inflammatory response, continuing the cycle. 
Recently, Parachikova and colleagues [6] found that there was increased gene expression of the inflammatory molecule, major histocompatibility complex (MHC) II in the hippocampus of AD cases with mild/moderate dementia. MHC class II was found primarily in the microglia and the increase in MHC class II was correlated with cognitive decline based on the mini-mental state exam (MMSE) score. MHC class II is responsible for displaying degraded foreign proteins to the cell surface for the recognition by CD4+ T lymphocytes. CD74, also known as the invariant chain, is known for its role in chaperoning the MHC class II molecules from the endoplasmic reticulum to the cell surface. CD74 blocks the peptide-binding site of MHC class II molecules during transportation from the ER to the cell surface [7].

Interestingly CD74 also mediates binding of the extracellular pro-inflammatory cytokine macrophage migration inhibitory factor (MIF) [8]. MIF is released in response to stress or an inflammatory response. MIF down-regulates the immunosuppressive effects of glucocorticoids and has been found to increase in the brain and cerebrospinal fluid in response to lipopolysaccharide [9]. Furthermore, MIF can be induced to form amyloid fibrils and can bind to $\mathrm{A} \beta[10,11]$. The role of $\mathrm{CD} 74$ as an MHC class II chaperone and as a receptor for MIF, both of which contribute to the pathology of $\mathrm{AD}$, lead us to believe that $\mathrm{CD} 74$ may play an important role in $\mathrm{AD}$. Yoshiyama determined that CD74 is increased in microglia of $\mathrm{AD}$ patients by means of immunohistochemistry, but did not examine neuronal CD74 [12]. Increased MIF mRNA was found in AD
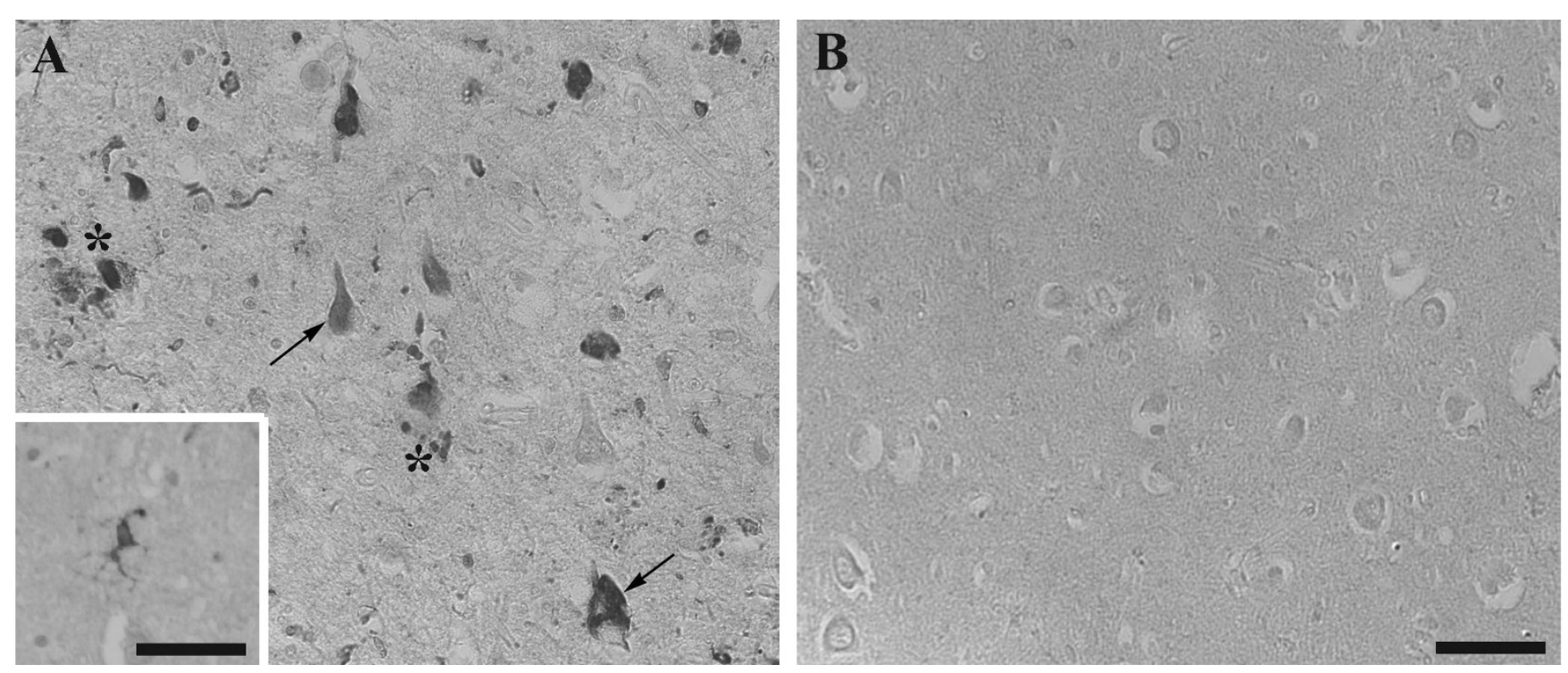

Figure I

Immunohistochemistry with the antibody to CD74 in AD (A) and control (B) hippocampus. CD74 strongly stained neurofibrillary tangles (arrows), amyloid- $\beta$ plaques $(*)$ and microglia (inset) in the $A D$ cases $(n=6)$, but not in controls $(\mathrm{n}=6)$. Scale Bar $=50 \mu \mathrm{m}$. patients in neurons [13]. Therefore, the aim of this study is to determine if $\mathrm{CD} 74$ is altered in $\mathrm{AD}$ patients in both the microglia and neurons.

\section{Results}

\section{Immunocytochemistry}

CD74 immunocytochemistry demonstrated labeling of microglial processes within the gray matter of the hippocampal pyramidal cell layer and the subiculum, and was most notable within microglial processes in and around senile (neuritic and cored) plaques. This finding is overall consistent with the literature on CD74 in AD brains. In addition, however, we noted strong immunolabeling of pyramidal neurons, both diffusely within the cytoplasm of pathologically normal neurons, as well as co-labeling of neurofibrillary pathology; in particular, neurofibrillary tangles, neuropil threads, and dystrophic neurites within neuritic senile plaques also showed strong immunoreactivity in a distribution similar to phospho-tau immunoreactivity. Labeling of amyloid plaque cores per se and diffuse plaques was not identified, nor was labeling of blood vessels affected by cerebral amyloid angiopathy. No labeling of granulovacuolar degeneration or Hirano bodies was seen. No significant immunolabeling of macroglia (astrocytes, oligodendrocytes) was present. Control tissue showed no immunolabeling, either of neurons, macroglia, or microglia (Figure 1A,B).

\section{Immunoblotting}

Immunoblot of brain homogenates prepared from $\mathrm{AD}$ and control hippocampus demonstrated protein bands at 
approximately 30-37 $\mathrm{kDa}$, consistent with reported CD74 isoforms (Figure 2A). Statistical analysis of the 30 $\mathrm{kDa}$ band showed a significantly higher level of CD74 in $\mathrm{AD}$ compared to control ( $\mathrm{p}=<0.01$ ) (Figure $2 \mathrm{C}$ ).

\section{Discussion}

$\mathrm{AD}$ is the most common neurodegenerative disorder, but the cause of $\mathrm{AD}$ is still unknown. Pro-inflammatory markers IL-1 $\beta$, IL-6, and TNF $\alpha$ are increased in AD patients as well as the anti-inflammatory marker IL-10 [4,5]. Increases in two additional inflammatory markers, MIF and MHC class II recently have been found in AD cases compared to age-matched controls $[6,8]$.

Immunohistochemistry results (Figure 1A,B) reveal that the MIF receptor CD74 is increased in NFTs and microglia of $\mathrm{AD}$ patients compared to age-matched controls. To our knowledge this is the first study to find increased CD74 expression in neurons. Immunoblot analyses confirmed our findings from the immunohistochemistry data in that CD74 was expressed at the correct molecular weight in both $\mathrm{AD}$ and control brains (Figure 2). Overall there was a significant increase in CD74 in AD compared to control cases, which may be related to the disease stage, with two $\mathrm{AD}$ cases being more severe than the others and likely containing more CD74-containing neurofibrillary pathology.

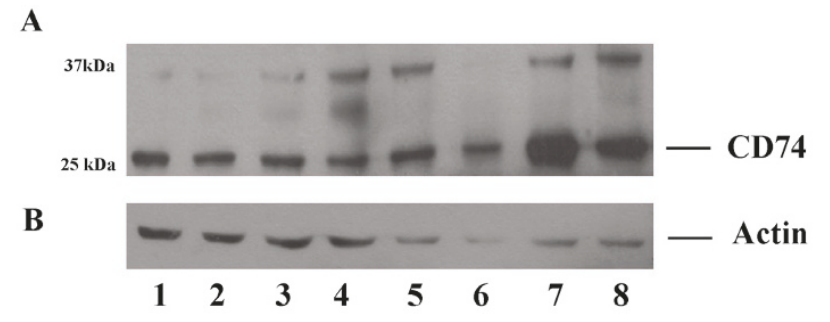

C

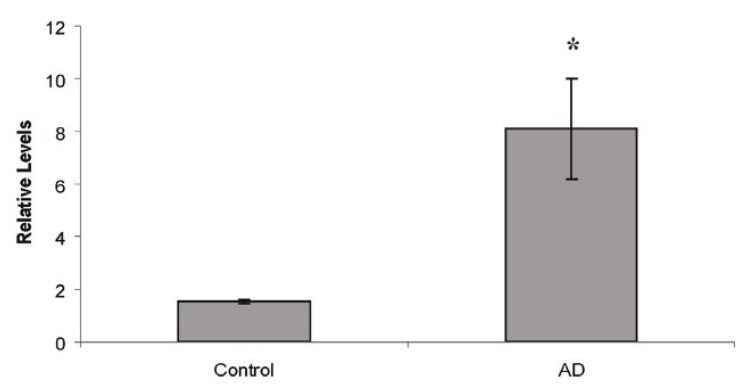

Figure 2

CD74 protein levels were assessed by Western blotting in four AD cases (lanes 5-8) and four controls (lanes I-4). (A) Western blot for CD74. (B) Actin. The relative quantification and statistical analysis shows significantly higher $(p=<0.01)$ levels of CD74 in AD verses control brain (C).
Additional cases will need to be analyized to confirm this. Insoluble fragments were found at the top of the blot, which may be due to the insoluble paired helical filaments that compose NFTs [14]. This study is consistent with previous findings that CD74 is increased in the microglia of AD brain, but sheds light that CD74 is important in NFTs as well.

The fact that CD74 is an extracellular surface receptor for MIF was only recently discovered [8]. MIF has been found in neurons of the hippocampus, hypothalamus, and cortex and is often increased in AD patients compared to controls [10]. CD74 is a high affinity binding protein for MIF and is necessary for MIF-induced activation of the extracellular-regulated-kinase (ERK) 1/2 MAP kinase cascade, cell proliferation, and prostaglandin $\mathrm{E}_{2}\left(\mathrm{PGE}_{2}\right)$ production [8]. In this regard, it is of interest to note that the ERK pathway is activated in AD [14-17] and elevated levels of $\mathrm{PGE}_{2}$ in $\mathrm{AD}$ are likely involved in $\mathrm{A} \beta$ production $[18,19]$. CD74 is mainly known as an MHC class II chaperone, which allows the MHC class II molecules to leave the endoplasmic reticulum and prevents binding of other proteins to the MHC II molecule. Stimulation of CD74 leads to NFKB activation, entry of CD74 stimulated cells into the $S$ phase, elevation of the DNA synthesis, cell division, and leads to cell proliferation and survival [20,21].

There is very little information on the role of CD74 in neurodegenerative diseases. Yoshiyama and colleagues [12] did determine that CD74 was increased in only resting or mildly active microglia of AD patients. Expression of pro-Cathespin $\mathrm{L}$, which is responsible for the degradation of CD74, was highly expressed in fully activated microglia, but not in resting or mildly active microglia. Therefore, in future studies, we will determine if increased CD74 in NFTs is due to a dysregulation of Cathsepin L [12].

NFTs are a hallmark characteristic of AD pathology and are a result of tau accumulation. Oxidative stress and activation of cell cycle regulators are associated with NFT formation $[22,23]$. Tau and neurofilament proteins contain a high content of lysine-serine-proline (KSP) domains, which makes them uniquely adapted to oxidative attack. Oxidative stress through the activation of the MAP kinase pathways leads to tau phosphorylation [24]. CD74 also increases in response to oxidation and when stimulated by MIF induces phosphorylation of ERK1/2 [8].

The cell cycle hypothesis of AD states that cell cycle disruptions occur in $\mathrm{AD}$ and that activation of cell cycle regulators precedes the formation of NFTs [25]. Furthermore, markers from each phase of the cell cycle have been accounted for in degenerating neurons, which has led some to hypothesize that cells may re-enter the cell cycle 
through to the $S$ phase, but for unknown reasons abort somatic division leading to degeneration of the neuron. CD74 regulates cell entry to the $S$ phase in B cells. Cyclin $\mathrm{E}$ is expressed on initiation of the S-phase and is upregulated following CD74 stimulation [21]. Whether there is a connection between CD74 activation and disruption of the cell cycle in degenerating neurons is unknown, but may be an indication as to why CD74 is found in NFTs. In conclusion, CD74 is increased in microglia and neurons in $\mathrm{AD}$ patients. NFTs had the greatest increase in CD74, while microglia CD74 was only minimally increased. Our results are the first to find an increase of CD74 in NFTs. The mechanism and importance of CD74 in neurons has yet to be elucidated and further studies need to be conducted.

\section{Methods Immunocytochemistry}

Postmortem hippocampal tissue from six confirmed AD patients (ages 87-67) and six aged matched control patients (ages 86-43) were fixed in methacarn (methanolchloroform-acetic acid; $6: 3: 1)$ overnight at $4{ }^{\circ} \mathrm{C}$, dehydrated in ascending ethanol and embedded in paraffin. Six micron sections were cut and placed on plus coated slides (Fisher Scientific, $25 \times 75 \times 1.0 \mathrm{~mm}$ ). Sections were then deparaffinized in xylene and hydrated through decending ethanol. Endogenous peroxidase was quenched with 3\% hydrogen peroxide/methanol. Nonspecific binding sites were blocked with $10 \%$ normal goat serum in TBS (150 mM Tris-buffered Saline, pH 7.6) followed by incubation in the primary antibody, CD74 (1:100, Santa Cruz). The sections were stained with the peroxidase anti-peroxidase method [26] with 3,3-diaminobenzidine (DAB) as the co-substrate as previously described.

\section{Immunoblotting}

Poly-acrylamide gel electrophoresis was performed on hippocampal and frontal cortex tissue from four AD and four control cases. Samples were homogenized in TBS and $10 \mu \mathrm{g}$ of protein was loaded per lane in Kelly's sample buffer. Proteins were resolved on 10\% SDS-PAGE gels and transferred to Immobilon-P, PVDF membrane (Millipore Corp., Billerica, MA). Membrane was probed with CD74 after non-specific binding sites were blocked with $10 \%$ non-fat milk in TBS, followed by HRP linked secondary (ICN). Proteins were detected with immobilon western chemiluminescent HRP substrate (Millipore Corp., Billerica, MA). The membrane was stripped with stripping reagent and re-probed with actin as an internal loading control.

\section{Statistical Analysis}

Densitometric analysis was performed with UN-SCAN-IT gel 6.1 software (Silk Scientific; Oren, UT). Significance was determined with the student t-Test.

\section{List of abbreviations}

$\mathrm{AD}$ : Alzheimer disease; $\mathrm{A} \beta$ : amyloid- $\beta$; DAB: 3,3-diaminobenzidine; ERK: extracellular-regulated-kinase; IL-1 $\beta$ : interleukin-1 $\beta$; IL-6: interleukin-6; KSP: lysine-serine-proline; MIF: macrophage migration inhibitory factor; MHC: major histocompatibility complex; MMSE: mini-mental state exam; NFT: neurofibrillary tangles; $\mathrm{PGE}_{2}$ : prostaglandin $\mathrm{E}_{2}$; TBS: Tris-buffered saline, TNFa: tumor necrosis factor $\alpha$.

\section{Competing interests}

The authors declare that they have no competing interests.

\section{Authors' contributions}

KJB and PLH carried out the immunocytochemistry; PLH, $\mathrm{RJC}$, and XWZ participated in data analysis and interpretation; and KJB, XWZ, GP, and MAS drafted the manuscript. KJB, MAS and GC conceived of the study and participated in the design of the study. All authors read and approved the final manuscript.

\section{Acknowledgements}

Work in the authors' laboratories was supported by the National Institutes of Health, the Alzheimer's Association and Philip Morris USA Inc. and Philip Morris International.

\section{References}

I. Zhu X, Raina AK, Perry G, Smith MA: Alzheimer's disease: the two-hit hypothesis. Lancet Neurol 2004, 3:219-226.

2. Webber KM, Casadesus G, Marlatt MW, Perry G, Hamlin CR, Atwood CS, Bowen RL, Smith MA: Estrogen bows to a new master: the role of gonadotropins in Alzheimer pathogenesis. Ann N Y Acad Sci 2005, I 052:20I-209.

3. Webber KM, Stocco DM, Casadesus G, Bowen RL, Atwood CS, Previll LA, Harris PL, Zhu X, Perry G, Smith MA: Steroidogenic Acute Regulatory Protein (StAR): Evidence of GonadotropinInduced Steroidogenesis in Alzheimer Disease. Mol Neurodegener 2006, I: | 4 .

4. Heneka MT, O'Banion MK: Inflammatory processes in Alzheimer's disease. I Neuroimmunol 2007, I 84:69-9I.

5. Rossi F, Bianchini E: Synergistic induction of nitric oxide by beta-amyloid and cytokines in astrocytes. Biochem Biophys Res Commun 1996, 225:474-478.

6. Parachikova A, Agadjanyan MG, Cribbs DH, Blurton-Jones M, Perreau V, Rogers J, Beach TG, Cotman CW: Inflammatory changes parallel the early stages of Alzheimer disease. Neurobiol Aging 2007, 28: 1821-1833.

7. Becker-Herman S, Arie G, Medvedovsky H, Kerem A, Shachar I: CD74 is a member of the regulated intramembrane proteolysis-processed protein family. Mol Biol Cell 2005, 1 6:506I-5069.

8. Leng L, Metz CN, Fang Y, Xu J, Donnelly S, Baugh J, Delohery T, Chen $Y$, Mitchell RA, Bucala R: MIF signal transduction initiated by binding to CD74. J Exp Med 2003, 197:|467-|476.

9. Lue H, Kleemann R, Calandra T, Roger T, Bernhagen J: Macrophage migration inhibitory factor (MIF): mechanisms of action and role in disease. Microbes Infect 2002, 4:449-460.

10. Lashuel HA, Aljabari B, Sigurdsson EM, Metz CN, Leng L, Callaway DJ, Bucala R: Amyloid fibril formation by macrophage migration inhibitory factor. Biochem Biophys Res Commun 2005, 338:973-980. 
II. Oyama R, Yamamoto H, Titani K: Glutamine synthetase, hemoglobin alpha-chain, and macrophage migration inhibitory factor binding to amyloid beta-protein: their identification in rat brain by a novel affinity chromatography and in Alzheimer's disease brain by immunoprecipitation. Biochim Biophys Acta 2000, 1479:91-102.

12. Yoshiyama Y, Arai K, Oki T, Hattori T: Expression of invariant chain and pro-cathepsin $\mathbf{L}$ in Alzheimer's brain. Neurosci Lett 2000, 290: I 25- I 28.

13. Fingerle-Rowson GR, Bucala R: Neuroendocrine properties of macrophage migration inhibitory factor (MIF). Immunol Cell Biol 200I, 79:368-375.

14. Perry G, Roder H, Nunomura A, Takeda A, Friedlich AL, Zhu X, Raina AK, Holbrook N, Siedlak SL, Harris PL, Smith MA: Activation of neuronal extracellular receptor kinase (ERK) in Alzheimer disease links oxidative stress to abnormal phosphorylation. Neuroreport 1999, 10:24II-24I5.

15. Zhu X, Castellani RJ, Takeda A, Nunomura A, Atwood CS, Perry G, Smith MA: Differential activation of neuronal ERK, JNK/SAPK and p38 in Alzheimer disease: the 'two hit' hypothesis. Mech Ageing Dev 200I, I 23:39-46.

16. Zhu X, Sun Z, Lee HG, Siedlak SL, Perry G, Smith MA: Distribution, levels, and activation of MEKI in Alzheimer's disease. J Neurochem 2003, 86:136-I42.

17. Mei M, Su B, Harrison K, Chao M, Siedlak SL, Previll LA, Jackson L, Cai DX, Zhu X: Distribution, levels and phosphorylation of Raf-I in Alzheimer's disease. J Neurochem 2006, 99:1377-1388.

18. Montine TJ, Sidell KR, Crews BC, Markesbery WR, Marnett LJ, Roberts LJ 2nd, Morrow JD: Elevated CSF prostaglandin E2 levels in patients with probable AD. Neurology 1999, 53:1495-I 498.

19. Hoshino T, Nakaya T, Homan T, Tanaka K, Sugimoto Y, Araki W, Narita M, Narumiya S, Suzuki T, Mizushima T: Involvement of prostaglandin E2 in production of amyloid-beta peptides both in vitro and in vivo. B Biol Chem 2007, 282:32676-32688.

20. Stumptner-Cuvelette $P$, Benaroch $P$ : Multiple roles of the invariant chain in MHC class II function. Biochim Biophys Acta 2002 I542: I-I3.

21. Starlets D, Gore Y, Binsky I, Haran M, Harpaz N, Shvidel L, BeckerHerman S, Berrebi A, Shachar I: Cell-surface CD74 initiates a sig naling cascade leading to cell proliferation and survival. Blood 2006, I 07:4807-48I6.

22. Nunomura A, Perry G, Pappolla MA, Wade R, Hirai K, Chiba S, Smith $M A:$ RNA oxidation is a prominent feature of vulnerable neurons in Alzheimer's disease. J Neurosci 1999, 19:1959-1964.

23. Busser I, Geldmacher DS, Herrup K: Ectopic cell cycle proteins predict the sites of neuronal cell death in Alzheimer's disease brain. J Neurosci 1998, 18:280I-2807.

24. Wataya T, Nunomura A, Smith MA, Siedlak SL, Harris PL, Shimoham S, Szweda LI, Kaminski MA, Avila J, Price DL, Cleveland DW, Sayre LM, Perry G: High molecular weight neurofilament proteins are physiological substrates of adduction by the lipid peroxidation product hydroxynonenal. I Biol Chem 2002, 277:4644-4648.

25. Neve RL, McPhie DL: The cell cycle as a therapeutic target for Alzheimer's disease. Pharmacol Ther 2006, I I I:99-II3.

26. Sternberger LA: Immunocytochemistry New York: Wiley; 1986
Publish with Biomed Central and every scientist can read your work free of charge

"BioMed Central will be the most significant development for disseminating the results of biomedical research in our lifetime. "

Sir Paul Nurse, Cancer Research UK

Your research papers will be:

- available free of charge to the entire biomedical community

- peer reviewed and published immediately upon acceptance

- cited in PubMed and archived on PubMed Central

- yours - you keep the copyright
BioMedcentral 